\title{
The Effects of Buoyancy Force on the Irreversibility of Three-Dimensional Step Flow in an Inclined Duct
}

\author{
M. Atashafrooz ${ }^{1^{*}}$, T. Asadi $^{2}$ \\ ${ }^{1}$ Department of Mechanical Engineering, Sirjan University of Technology, Sirjan, Iran \\ E-mail: Meysam.atashafrooz@yahoo.com,m.atashafrooz@sirjantech.ac.ir \\ ${ }^{2}$ Department of Chemical Engineering, Sirjan University of Technology, Sirjan, Iran \\ E-mail: t.asadi@sirjantech.ac.ir \\ *corresponding author
}

\begin{abstract}
This research deals with the study of the irreversibility of three-dimensional mixed convection flow in an inclined duct with step. To reach this goal, an analysis of entropy generation is carried out according to the second law of thermodynamics. The effects of buoyancy force on the flow irreversibility are analyzed with all details. The results show that the values of entropy generation number and Bejan number are intensively dependent on the Grashof number and duct inclination angle, so that the effects of Grashof number on the mentioned parameters are much higher for the vertical ducts.
\end{abstract}

Keywords: Flow irreversibility, entropy generation, Bejan number, buoyancy force, threedimensional step flow

\section{Introduction}

Analysis of the hydrodynamic and thermal behaviors of the step flows has been extensively studied during last decades (Iwai et al. 2000, Uruba et al. 2007, Nie et al. 2009, Selimefendigil and Oztop 2013, Atashafrooz et al. 2015, Selimefendigil and Oztop 2016). This continued attention is actually due to the important influence of this type of flow in the design of many engineering equipment, such as combustion chambers, power generating equipment, cooling of electronic systems, and heat exchangers. In fact, the step flow has the most specifications of separation flows and is considered as benchmark geometry (Chen et al. 2006, Atashafrooz and Gandjalikhan Nassab 2012, Mohammed et al. 2015).

Conservation of the useful energy is one of the extremely important goals in the design of some of mentioned engineering applications. In the process components of the energy systems, the irreversibility destroys the available energy. According to the second law of thermodynamics, the irreversibility can be minimized to save and optimize the useful energy, but it cannot be eschewed completely (Bejan 1994, Bejan 1996). So far, several different techniques and criteria have been proposed to find the irreversibility of thermal systems and also to optimize them. Analysis of entropy generation is one of these optimal design criteria which measures the destruction of available energy in a system (Bejan 1994, Bejan 1996). 
Convection fluid flows are accompanied by irreversibility due to viscous shear stresses and heat transfer (Erbay et al. 2004, Dagtekin et al. 2007, Bahaidarah and Sahin 2013). In fact, the gradients of velocity and temperature are the only sources of entropy generation in these flows. Entropy generation analysis in convection fluid flows has been widely studied in the last years in order to determine the effects of various parameters on irreversibility (Mohaghegh and Esfahani 2016, Mamourian et al. 2016, Aghaei et al. 2016, Oztop et al. 2017).

From the viewpoint of entropy generation, the analysis of the step flows is also investigated by several researchers. In fact, this subject is important due to the special considerations of hydrodynamic and thermal behaviors of flow in separation regions. Among two-dimensional (2D) works, investigation of entropy generation in 2-D forced convection flow over a backward facing step (BFS) is done by Abu-Nada $(2006,2008)$. In those papers, the effects of several different parameters such as bleeding conditions and Reynolds numbers on the distributions of entropy generation and Bejan numbers were presented. Also, Atashafrooz et al. $(2011,2014)$ studied investigation of entropy generation in laminar forced convection flow over a 2-D recess including two steps in a horizontal duct. The results of those researches show that the values of entropy generation number and Bejan numbers are affected from the step inclination angle, recess length, Reynolds number and bleeding conditions. In another study, entropy generation rate over a 2-D BFS was numerically calculated by Nassab et al. (2014). Results of that paper show that he use of suction produces less irreversibility compared to the use of baffles. In one of the latest researches, effects of magnetic field on the entropy generation rate for mixed convection of nanofluid flow over a BFS were studied by Selimefendigil and Öztop (2015). In that work, it was shown that the total entropy generation increases by increasing the Reynolds number and nanoparticles volume fraction, while it decreases as the Hartmann number increases.

About the analysis of irreversibility in three-dimensional step flow, a few studies has been done. For example, the effects of the flow bleeding on the entropy generation rate over a threedimensional BFS in a horizontal duct were analyzed by Kooshki et al. (2012). In that study, researchers show that the suction and blowing coefficients have a great effect on the rates of total entropy generation and heat transfer in separated convection flow.

To the best of the authors' knowledge, analysis of entropy generation in three-dimensional mixed convection flow over steps is not still studied. In mixed convection flow, the continuity and momentum equations are coupled with energy equation, such that temperature and flow fields mutually influence each other. Therefore, taking into account the interactions between two sources of entropy generation (viscous shear stresses and heat transfer) is very important in mixed convection flow. In fact, in mixed convection flow, the buoyancy force is the most important parameter which affected the rate of entropy generation. According to what was said above, the main goal of this research is to study the effects of buoyancy force on the irreversibility of threedimensional step flow in an inclined duct. Toward this purpose, the irreversibility is evaluated using entropy generation number based on the second law of thermodynamics.

\section{Theory and Numerical Solution}

\subsection{Problem Description}

The geometry of the problem in the present research is a three-dimensional BFS in an inclined duct. Schematic of the computational domain along with the relevant dimensions considered in this study is shown in Figure 1. The BFS is considered inclined and is mounted onto the bottom wall of the duct with $\beta=45^{\circ}$. The expansion $(E R=H / h)$ and aspect $(A R=D / h)$ ratios of this duct are equal to 2 and 4 , respectively. Also, the duct inclination angle is denoted as $\theta$, which is measured from the horizontal sense and can be changed from $0^{\circ}$ to $90^{\circ}$. 


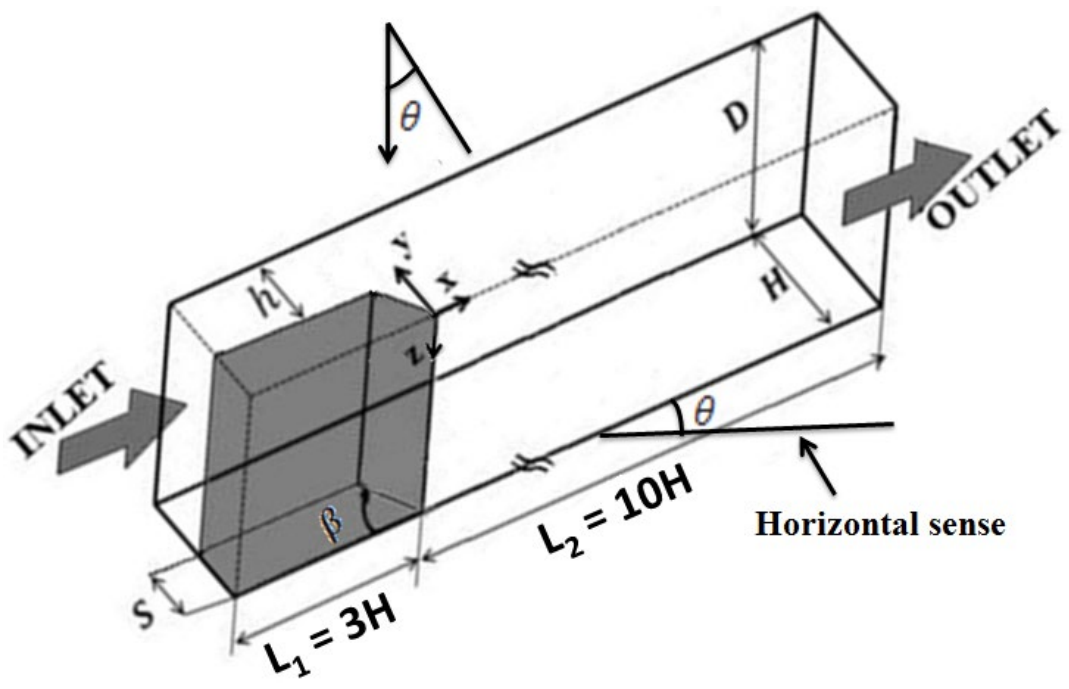

Fig. 1. Schematics of the computational domain along with the relevant dimensions

The boundary conditions of this problem are presented in Table 1.

\section{Flow boundary conditions}

$$
u=U_{0}, v=w=0.0 \mathrm{u}=
$$

Inlet section

$$
\begin{gathered}
\mathrm{U}_{0}, \mathrm{v}=\mathrm{w}=0.0 \mathrm{u}= \\
\mathrm{U}_{0}, \mathrm{v}=\mathrm{w}=0.0
\end{gathered}
$$

\section{Bottom wall}

(include step

$$
u=v=w=0.0
$$

surfaces)

Top wall

$$
u=v=w=0.0
$$

$$
\frac{\partial u}{\partial x}=\frac{\partial v}{\partial x}=\frac{\partial w}{\partial x}=0
$$

Thermally fully developed

\section{conditions}

$$
T=T_{\text {in }}
$$

$$
T=T_{h}>T_{\text {in }}
$$

$T=T_{c}=T_{\text {in }}$

Thermal boundary

Table 1. Flow and thermal boundary conditions for the problem under the study

\subsection{Entropy Generation Analysis}

As it was mentioned before, the purpose of this research is the study the effects of buoyancy force on the flow irreversibility for the problem described in Figure 1. This goal can be achieved by computing the volume rate of entropy generation. According to the second law of thermodynamics, this rate at each grid point in the flow domain can be calculated with the sum of entropy generation due to heat transfer and friction fluid flow.

The entropy generation rate due to heat transfer is found from the temperature gradients as follow (Bahaidarah and Sahin 2013, Mohaghegh and Esfahani 2016): 


$$
\left.S_{g}\right)_{H}=\frac{k}{T^{2}}\left[\left(\frac{\partial T}{\partial x}\right)^{2}+\left(\frac{\partial T}{\partial y}\right)^{2}+\left(\frac{\partial T}{\partial z}\right)^{2}\right]
$$

Whereas the rate of entropy generation due to friction fluid flow is related to the viscous shear stresses, which can be computed using the following equation (Bahaidarah and Sahin 2013, Mohaghegh and Esfahani 2016):

$$
\left.S_{g}\right)_{V}=\frac{\mu}{T}\left\{\begin{aligned}
2\left[\left(\frac{\partial u}{\partial x}\right)^{2}+\left(\frac{\partial v}{\partial y}\right)^{2}\right. & \left.+\left(\frac{\partial w}{\partial z}\right)^{2}\right]+\left[\left(\frac{\partial u}{\partial y}\right)+\left(\frac{\partial v}{\partial x}\right)\right]^{2} \\
& +\left[\left(\frac{\partial u}{\partial z}\right)+\left(\frac{\partial w}{\partial x}\right)\right]^{2}+\left[\left(\frac{\partial v}{\partial z}\right)+\left(\frac{\partial w}{\partial y}\right)\right]^{2}
\end{aligned}\right\}
$$

Therefore, the entropy generation rate is expressed as (Bahaidarah and Sahin 2013, Mohaghegh and Esfahani 2016):

$$
\begin{aligned}
& \left.\left.S_{g}=S_{g}\right)_{H}+S_{g}\right)_{V}=\frac{k}{T^{2}}\left[\left(\frac{\partial T}{\partial x}\right)^{2}+\left(\frac{\partial T}{\partial y}\right)^{2}+\left(\frac{\partial T}{\partial z}\right)^{2}\right] \\
& +\frac{\mu}{T}\left\{2\left[\left(\frac{\partial u}{\partial x}\right)^{2}+\left(\frac{\partial v}{\partial y}\right)^{2}+\left(\frac{\partial w}{\partial z}\right)^{2}\right]+\left[\left(\frac{\partial u}{\partial y}\right)+\left(\frac{\partial v}{\partial x}\right)\right]^{2}+\left[\left(\frac{\partial u}{\partial z}\right)+\left(\frac{\partial w}{\partial x}\right)\right]^{2}+\left[\left(\frac{\partial v}{\partial z}\right)+\left(\frac{\partial w}{\partial y}\right)\right]^{2}\right.
\end{aligned}
$$

The above equation can be dimensionless as (Abu-Nada 2008, Atashafrooz et al. 2014, Kooshki et al. 2012):

$$
\left.\begin{array}{c}
N s=N s_{H}+N s_{V}=\left[\left(\frac{\partial \Theta}{\partial X}\right)^{2}+\left(\frac{\partial \Theta}{\partial Y}\right)^{2}+\left(\frac{\partial \Theta}{\partial Z}\right)^{2}\right] \\
+\Psi\left\{\left[\left(\frac{\partial U}{\partial X}\right)^{2}+\left(\frac{\partial V}{\partial Y}\right)^{2}+\left(\frac{\partial W}{\partial X}\right)^{2}\right]+\left[\left(\frac{\partial U}{\partial Y}\right)+\left(\frac{\partial V}{\partial X}\right)\right]^{2}\right. \\
+\left[\left(\frac{\partial U}{\partial Z}\right)+\left(\frac{\partial W}{\partial X}\right)\right]^{2}+\left[\left(\frac{\partial V}{\partial Z}\right)+\left(\frac{\partial W}{\partial Y}\right)\right]^{2}
\end{array}\right\}
$$

It should be mentioned that, the dimensionless parameters applied in this formulation are defined as follows:

$$
\begin{aligned}
& (X, Y, Z)=\left(\frac{x}{H}, \frac{y}{H}, \frac{z}{H}\right),(U, V, W)=\left(\frac{u}{U_{0}}, \frac{y}{U_{0}}, \frac{z}{U_{0}}\right), \theta=\frac{T-T_{c}}{T_{h}-T_{c}}, \\
& N s=\frac{S_{g} H^{2}}{k \tau^{2}}, \tau=\frac{T_{h}-T_{c}}{T_{c}}, B r=\frac{\mu U_{0}^{2}}{k\left(T_{h}-T_{c}\right)}, \Psi=\frac{B r}{\tau}
\end{aligned}
$$

Also, the total entropy generation number that shows the amount of flow irreversibility, can be written as (Abu-Nada 2008, Atashafrooz et al. 2014, Kooshki et al. 2012):

$$
N s_{t}=\int_{\forall} N s(X, V, Z) d \forall
$$


Where $\forall$ is the volume of flow domain. Another important parameter in analysis of the flow irreversibility is the Bejan number (Abu-Nada 2008, Atashafrooz et al. 2014, Kooshki et al. 2012):

$$
B e=\frac{N s_{H}}{N s_{H}+N s_{V}}
$$

As is clear from the above definition, Bejan number represents ratio of the entropy generation due to heat transfer to the mixed entropy generation rate. Also, the average Bejan number inside the flow domain is defined using the following equation (Abu-Nada 2008):

$$
B e_{\text {ave }}=\frac{1}{\forall} \int_{\forall} B e(X, V, Z) d \forall
$$

As it is clearly seen from the above equations, the velocity and temperature fields are required to calculate the entropy generation rate and Bejan number. To obtain these fields, it is necessary to solve the governing equations which are the conservation of mass, momentum, and energy. For incompressible, steady and three-dimensional mixed convection flow, the dimensionless form of these equations can be written as follows:

$$
\begin{aligned}
& \frac{\partial U}{\partial X}+\frac{\partial V}{\partial Y}+\frac{\partial W}{\partial Z}=0 \\
& U \frac{\partial U}{\partial X}+V \frac{\partial U}{\partial Y}+W \frac{\partial U}{\partial Z}=-\frac{\partial P}{\partial X}+\frac{1}{\operatorname{Re}}\left(\frac{\partial^{2} U}{\partial X^{2}}+\frac{\partial^{2} U}{\partial Y^{2}}+\frac{\partial^{2} U}{\partial Z^{2}}\right)+\frac{G r \sin \theta}{\mathrm{Re}^{2}} \Theta \\
& U \frac{\partial V}{\partial X}+V \frac{\partial V}{\partial Y}+W \frac{\partial V}{\partial Z}=-\frac{\partial P}{\partial Y}+\frac{1}{\operatorname{Re}}\left(\frac{\partial^{2} V}{\partial X^{2}}+\frac{\partial^{2} V}{\partial Y^{2}}+\frac{\partial^{2} V}{\partial Z^{2}}\right)+\frac{G r \cos \theta}{\operatorname{Re}^{2}} \Theta \\
& U \frac{\partial W}{\partial X}+V \frac{\partial W}{\partial Y}+W \frac{\partial W}{\partial Z}=-\frac{\partial P}{\partial Z}+\frac{1}{\operatorname{Re}}\left(\frac{\partial^{2} W}{\partial X^{2}}+\frac{\partial^{2} W}{\partial Y^{2}}+\frac{\partial^{2} W}{\partial Z^{2}}\right) \\
& U \frac{\partial \Theta}{\partial X}+V \frac{\partial \Theta}{\partial Y}+W \frac{\partial \Theta}{\partial Z}=\frac{1}{\operatorname{Re} \operatorname{Pr}}\left(\frac{\partial^{2} \Theta}{\partial X^{2}}+\frac{\partial^{2} \Theta}{\partial Y^{2}}+\frac{\partial^{2} \Theta}{\partial Z^{2}}\right)
\end{aligned}
$$

In these equations:

$$
P=\frac{p}{U_{0}^{2}}, \operatorname{Re}=\frac{\rho U_{0} H}{\mu}, \operatorname{Pr}=\frac{\vartheta}{\alpha}, G r=\frac{\gamma g\left(T_{h}-T_{c}\right) H^{3}}{\vartheta^{2}}
$$

It should be mentioned that in the equations (9) to (13), the physical properties of the fluid are considered constant except for the density in the body forces, which is modeled by the Bosinesque approximation. In fact, the last term on the right-hand side of equations (10) and (11) are related to this approximation.

\subsection{Numerical Solution and Validation}

Numerical solution of partial differential equations appearing in the present work was previously described in full details by Atashafrooz and Gandjalikhan Nassab 2012, Atashafrooz et al. 2014. Therefore, it is not discussed here to avoid repeating. However, a summary of highlights of this solution can be expressed as follow: 
The numerical solution of the equations (9) to (13) is performed using the CFD techniques with the SIMPLE algorithm (Patankar and Spalding 1972), when the convergence of solutions is checked using a yardstick taken as the values of absolute residuals in these equations become less than $10^{-5}$.

$\checkmark$ An optimum grid of $460 \times 40 \times 60$ is considered to solve the governing equations according to the results of grid independence study, when the blocked off method is applied to simulate the surfaces of inclined step (Atashafrooz and Gandjalikhan Nassab 2012). Also, the calculations time with this grid is about 520 min using a personal computer Intel (R), Core(TM) i5, CPU $2.53 \mathrm{GHz}$ and 4.00 GB of RAM.

It is necessary to mention that to validate the results of numerical calculations of present research, several case problems were solved in the previous studies by the author (Atashafrooz and Gandjalikhan Nassab 2012, Atashafrooz et al. 2014). Therefore, they are not repeated here for brevity.

\section{Results and Discussions}

First, in order to demonstrate the effects of buoyancy force on the flow irreversibility, distributions of entropy generation number $(N s)$ along the bottom wall are plotted in Figure 2 at six different Grashof numbers $(G r)$. A same trend is seen from Figure 2 for the variations of $N s$ at each value of Grashof number. According to this figure, the entropy generation number starts from a minimum value at the step corner on the bottom wall. Downstream the step location, the entropy generation number has a local maximum value inside the recirculation zone because of the back vortex flow. While at the reattachment point, this parameter has a very low value. After the reattachment point, the $N s$ increases sharply and reaches to its maximum value and finally approaches to a constant value due to the fully developed condition.

(a) $G r=0.0$

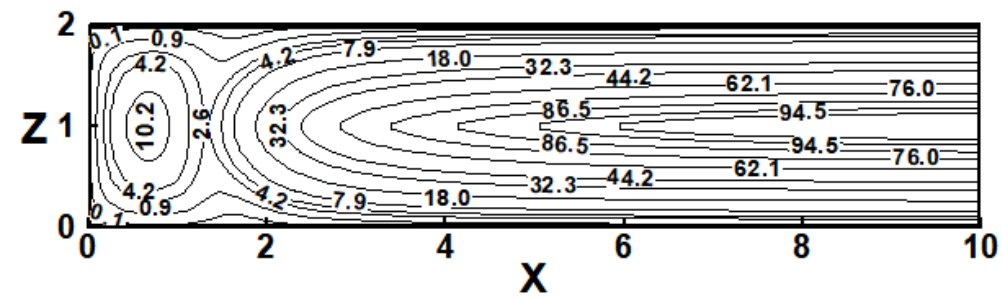

(b) $G r=2000$

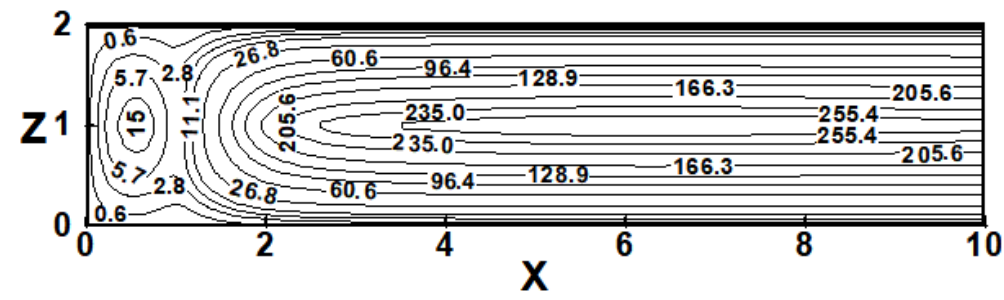

(c) $G r=4000$

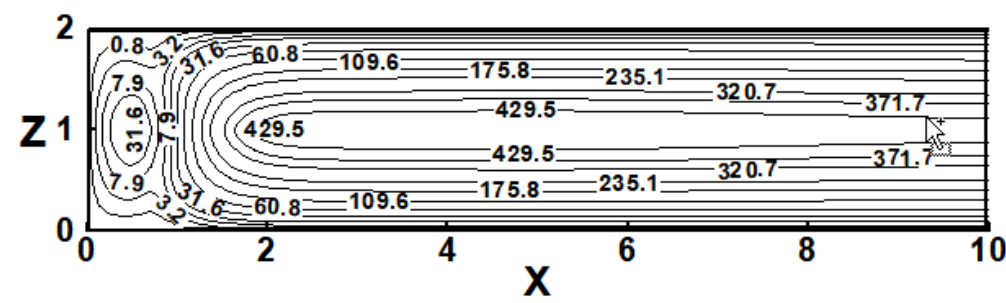


(d) $G r=6000$

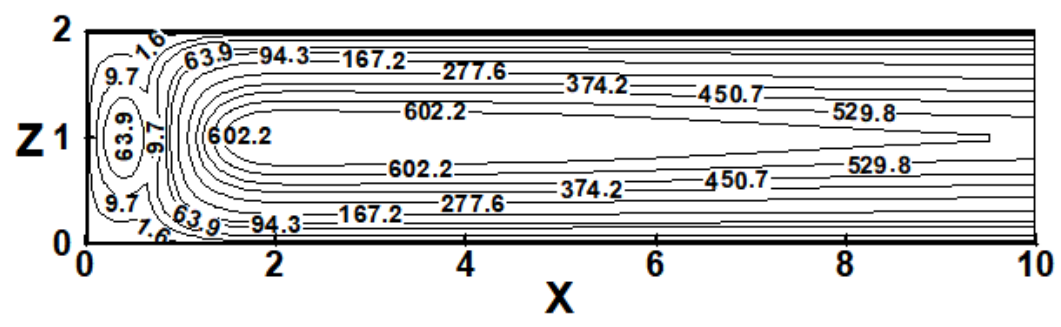

(e) $G r=8000$

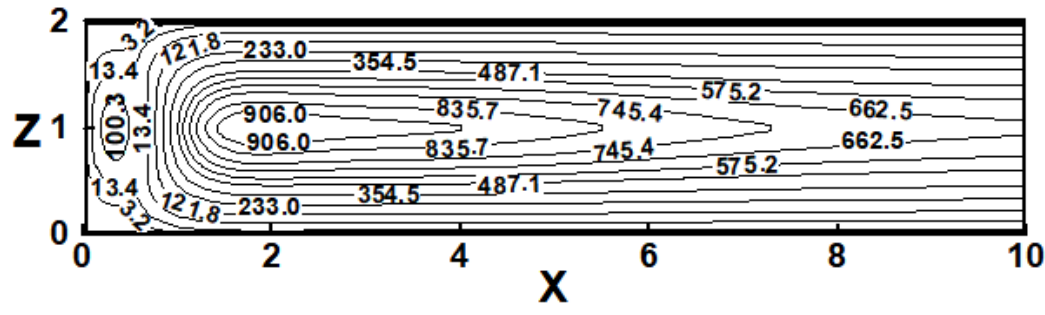

(f) $G r=10000$

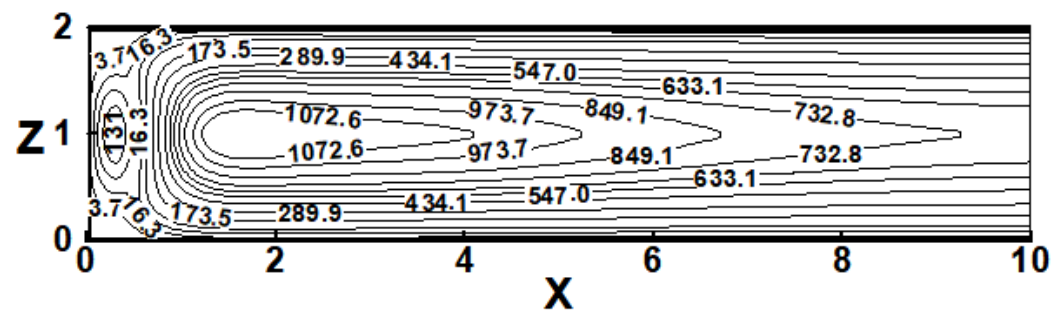

Fig. 2. Effect of Grashof number on the contours of entropy generation number along the bottom wall, $\mathrm{Re}=100, \Psi=1, \theta=30^{\circ}$

To have a better view of these behaviors, distributions of $N s$ along the centerline of the bottom wall are shown in Figure 3 for different values of $G r$. In addition to the above mentioned behaviors, two other important points are also clear from the $N s$ distribution at each value of $G r$.

First, in cross flow direction, entropy generation values near the side walls are much less than other areas of the bottom wall.

Secondly, in the axial direction of flow, the values of $N s$ in the recirculation region are much smaller than other areas of the bottom wall.

As it is revealed from Figures 2 and 3, the Grashof number has a considerable effect on the flow pattern and the flow irreversibility. It can be concluded from these figures that the extent of recirculation zone is strongly influenced from the values of $G r$. In fact, the length of reattachment point in the recirculation zone decreases by increasing the Grashof number, such that the highest recirculation zone is related to $G r=0$ (forced convection).

Besides, these figures clearly show that the value of entropy generation number increases significantly by increasing the Grashof numbers. 


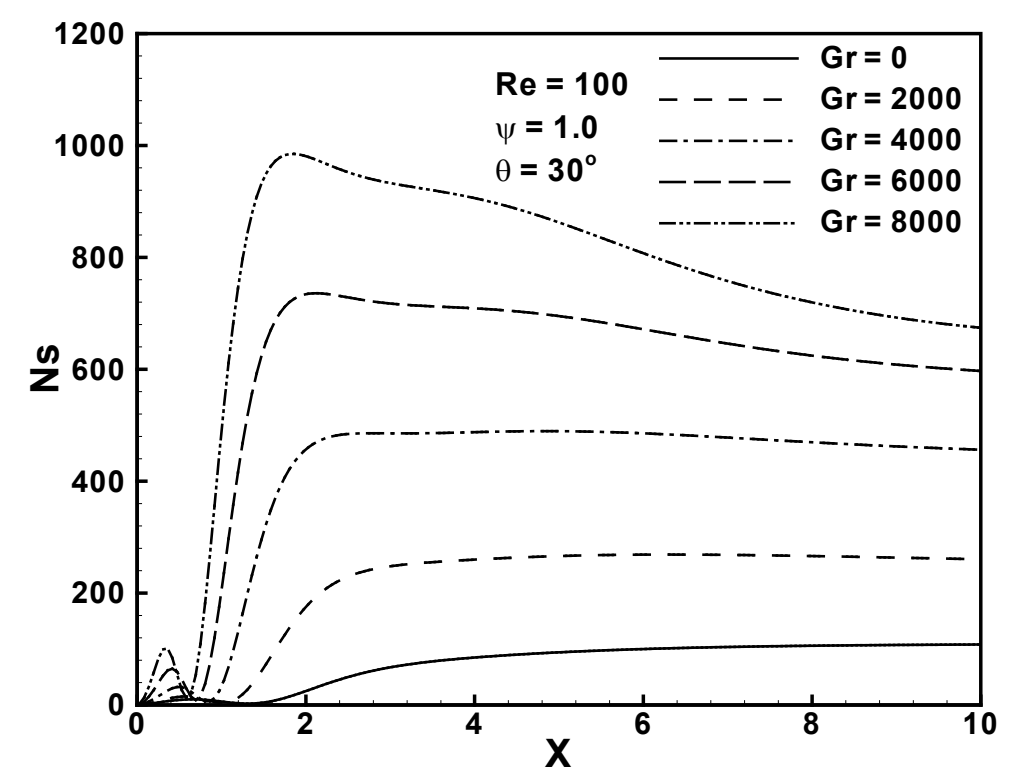

Fig. 3. Effect of Grashof number on the distributions of entropy generation number along the centerline of the bottom wall

The above mentioned results can be analyzed and interpreted by looking at Equations (3) and (4). According to what is explained in the description of these equations, viscous shear stresses (gradients of velocity) and heat transfer (temperature gradients) are the only sources of entropy generation. To study the effects of $G r$ on the entropy generation number due to the heat transfer $\left(N s_{H}\right)$, Figure 4 is presented. As it is seen from this figure, there are similar trends for the $N s_{H}$ distributions at each value of $G r$. Figures 4(a)-4(f) present that the minimum value of the $N s_{H}$ occurs at the step corner, where the temperature gradients are almost zero. Also, this variable increases sharply in the recirculation regions and reaches to its maximum value near the reattachment point. Finally, $N s_{H}$ decreases and approach to a constant value due to the constant temperature gradients. For better understanding of these behaviors, distributions of $N s_{H}$ along the centerline of the bottom wall are presented in Figure 5 for different values of $G r$. 
(a) $G r=0.0$

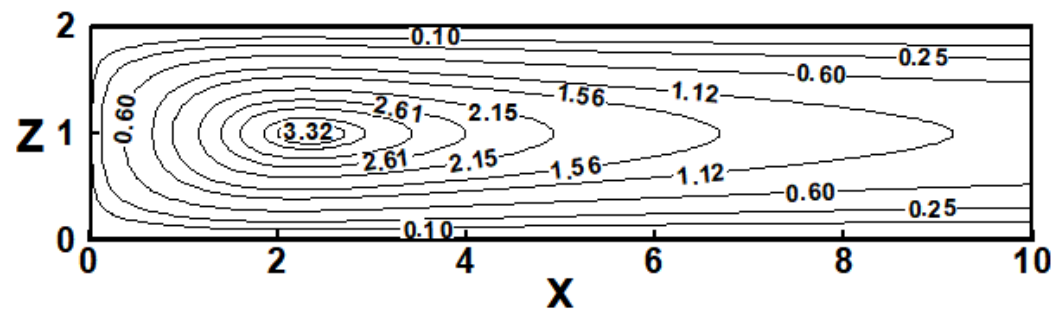

(b) $G r=2000$

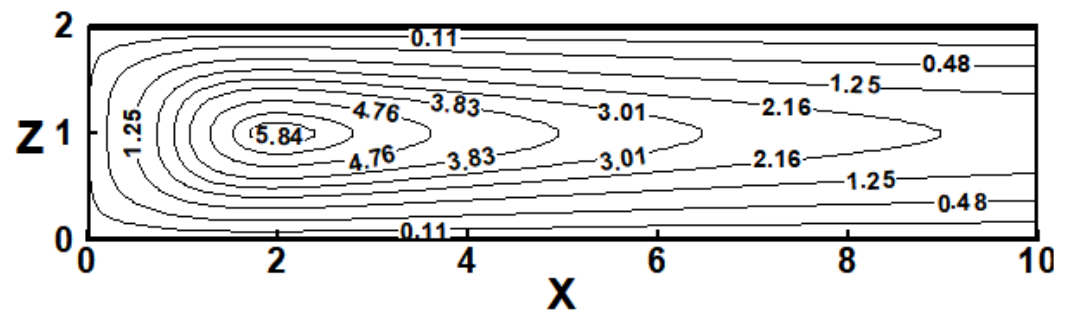

(c) $G r=4000$

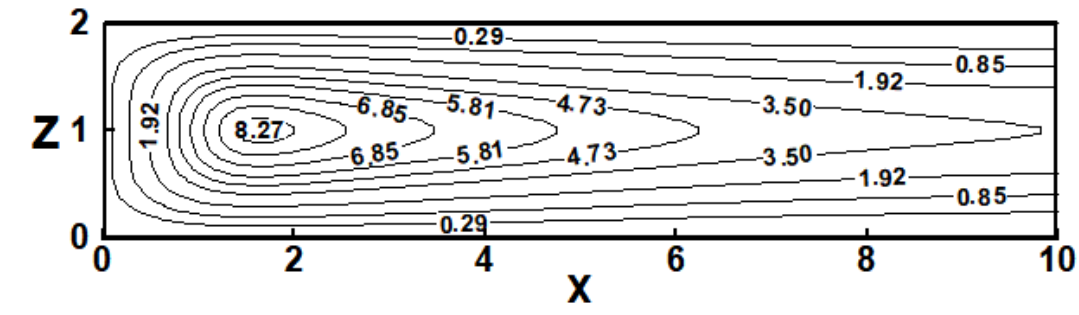

(d) $G r=6000$

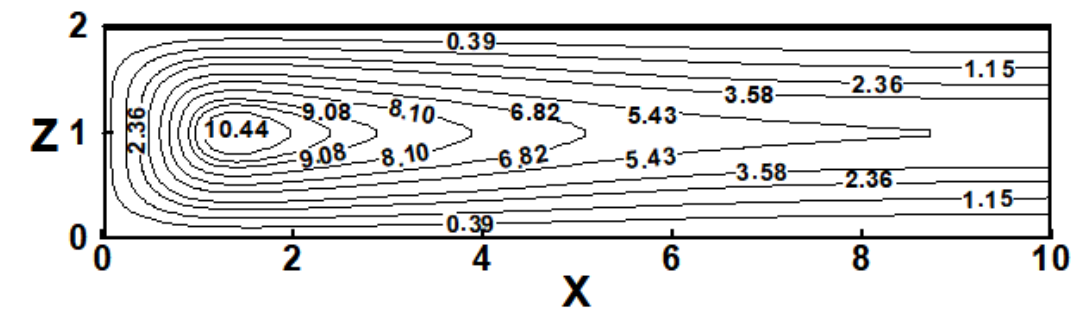

(e) $G r=8000$
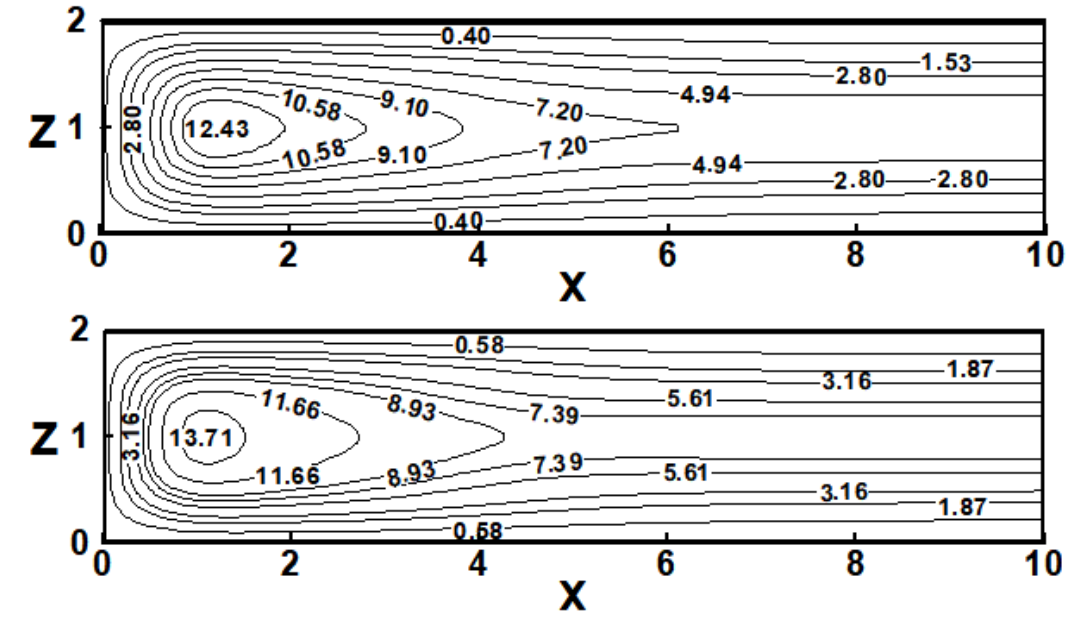

Fig. 4. Effect of Grashof number on the contours of entropy generation number due to heat transfer along the bottom wall, $\mathrm{Re}=100, \Psi=1, \theta=30^{\circ}$ 
Moreover, it is observed from Figures 4 and 5 that the distributions of $N s_{H}$ are significantly dependent on the Grashof number. According to these figures, an enhancement occurs in the values of $N s_{H}$ by increasing the value of $G r$, such that the highest values of this variable on the bottom wall are related to high values of $G r$.

Comparison of $N s_{H}$ distributions in Figures 4 and 5 with $N s$ distributions shown in Figures 2 and 3 demonstrates that with the exception of regions near the reattachment point, the values of $N s_{H}$ are very smaller in comparison with $N s$ values. Therefore, it can be concluded that except for the mentioned regions, contribution of viscous shear stresses in entropy generation $\left(N s_{V}\right)$ is much higher than the contribution of temperature gradients $\left(N s_{H}\right)$. In addition, it is very clear from this comparison that this contribution increases with increasing the Grashof number. Therefore, it can be said with certainty that the enhancement of entropy generation number against the $G r$ is due to the increase of two effective parameters of $N s_{H}$ and $N s_{V}$. But it should be noted that this enhancement is more due to the significant increase of $N s_{V}$ against the value of Grashof number.

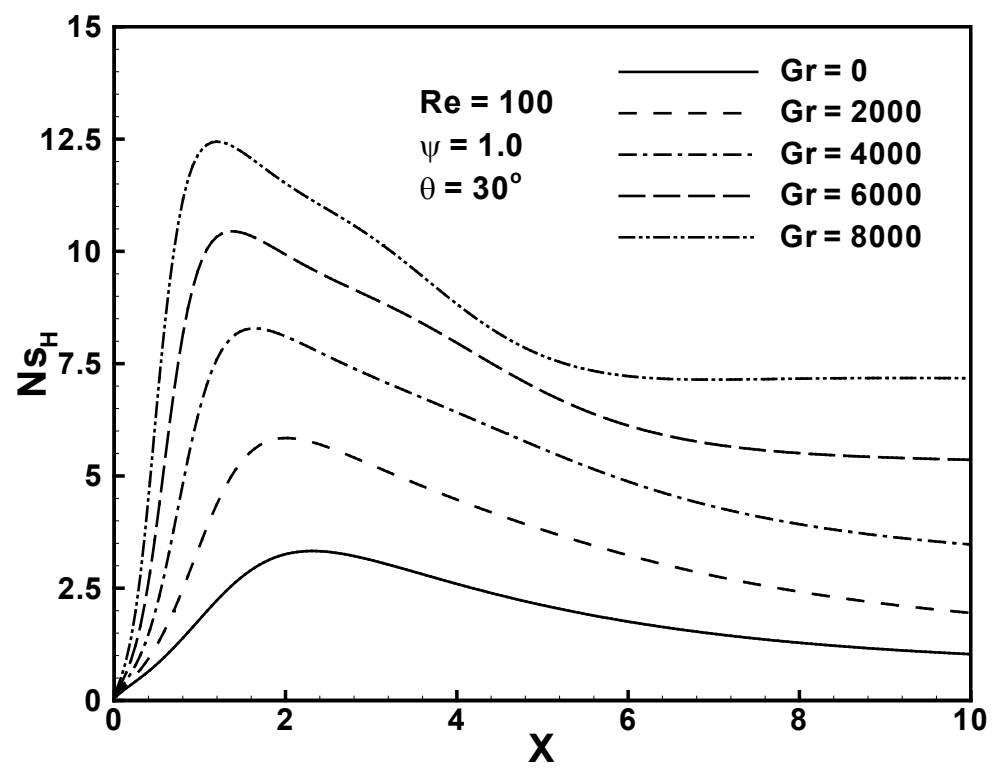

Fig. 5. Effect of Grashof number on the distributions of entropy generation number due to heat transfer along the centerline of the bottom wall

In order to show more clearly the contribution of each source of entropy generation, distributions of Bejan number $(\mathrm{Be})$ on the bottom wall and also along the mid-plane of this wall are presented in Figures 6 and 7. 
(a) $G r=0.0$

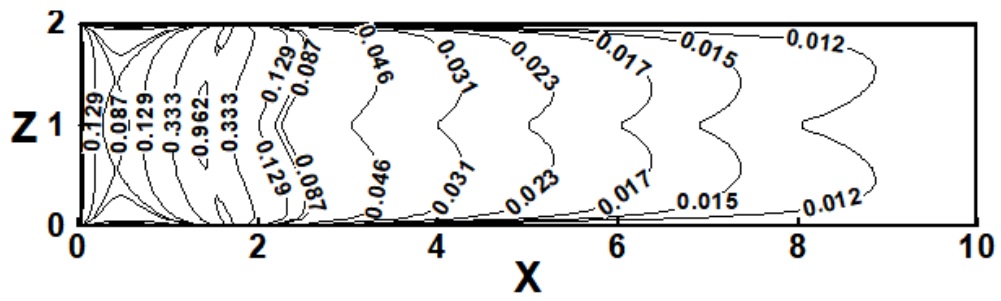

(b) $G r=2000$

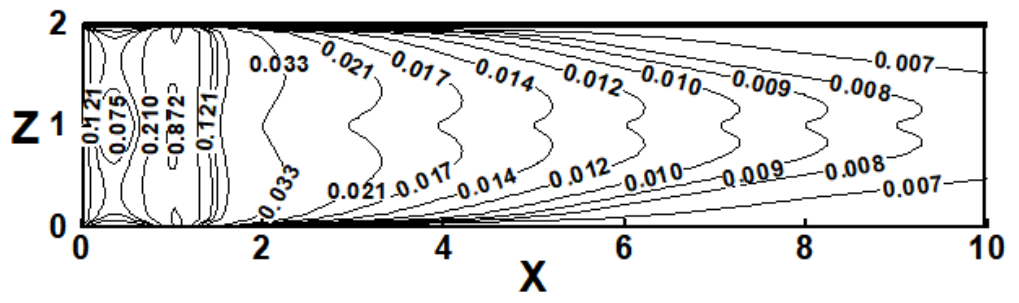

(c) $G r=4000$

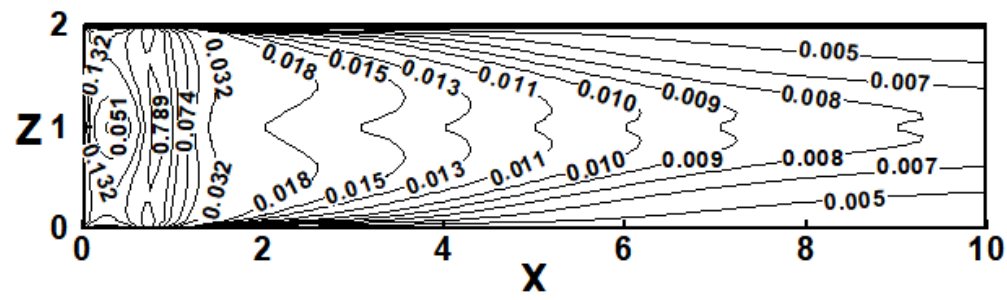

(d) $G r=6000$

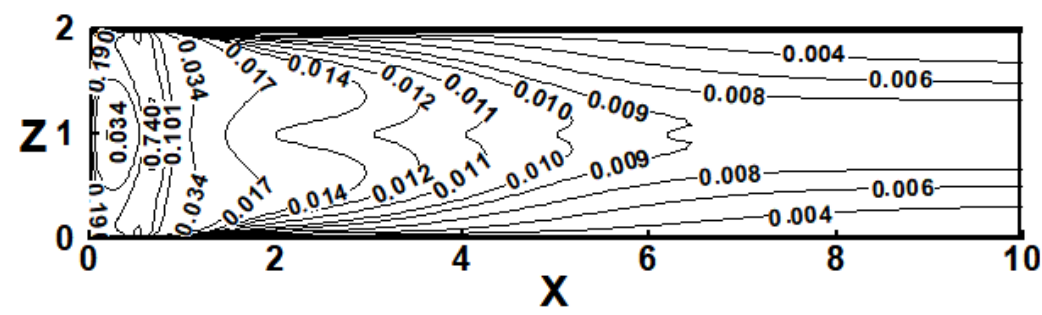

(e) $G r=8000$

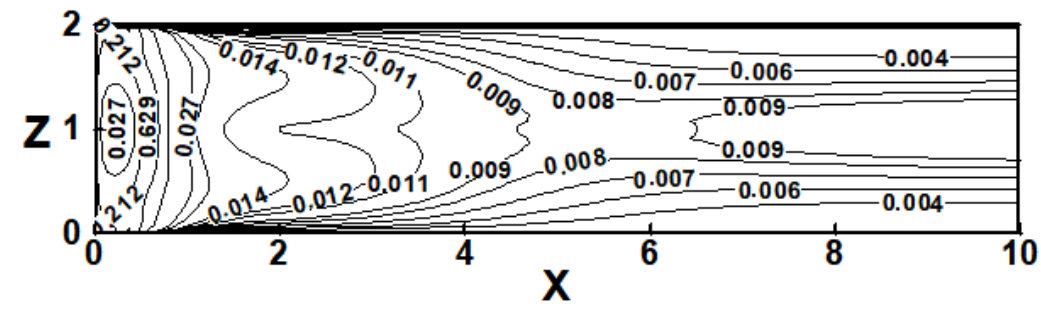

(f) $G r=10000$

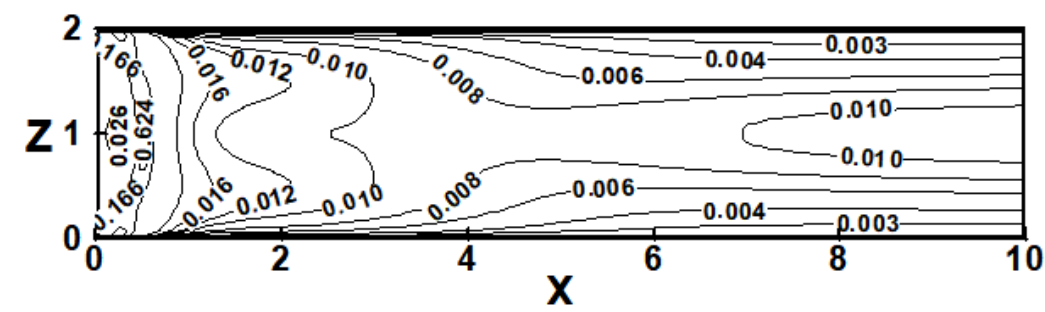

Fig. 6. Effect of Grashof number on the contours of Bejan number along the bottom wall, $\operatorname{Re}=100, \Psi=1, \theta=30^{\circ}$ 


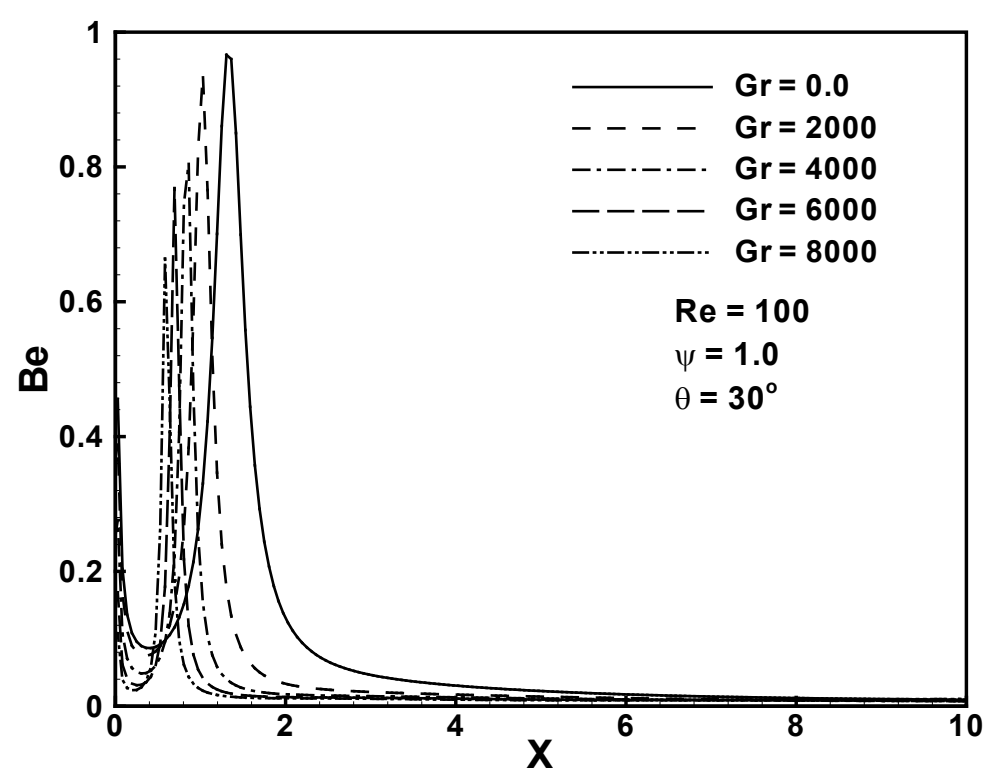

Fig. 7. Effect of Grashof number on the distributions of Bejan number along the centerline of the bottom wall

Based on the definition of the Bejan number which is described in Equation (7), the precise analysis of these figures confirms the previously mentioned results. In fact, it can be found from these figures that in regions where the Bejan number tends to be maximized, the contribution of temperature gradients in the entropy generation $\left(N s_{H}\right)$ is significant. While in the other regions, this contribution is vary smaller. In addition to what was said, Figures 6 and 7 clearly show that any increase in the value of $G r$ causes a decrease in the maximum value of $B e$. This trend is due to this fact that the increase rate of $N s_{H}$ with increasing Grashof number is smaller than the increase rate of $N s_{V}$ against the value of $G r$.

Originally, the amount of irreversibility of the convective flows can be determined by evaluating the total entropy generation number $\left(N s_{t}\right)$ and average Bejan number $\left(B e_{\text {ave }}\right)$. In the mixed convection problems, beside of the Grashof number, the duct inclination angle $(\theta)$ is also one of the main parameters that can be affected on the flow irreversibility. Therefore, in the next figures and discussions, an attempt is made to study the effects of mentioned parameters $(\mathrm{Gr}$ and $\theta$ ) on the $N s_{t}$ and $B e_{\text {ave }}$ inside the flow domain under study, which is restricted by: $0 \leq x \leq 10 H, 0 \leq y \leq 10 H$, and $0 \leq z \leq D$.

It can be observed from Figure 8 that the Grashof number and duct inclination angle have a significant effect on the $N s_{t}$. This figure clearly shows that increasing both $G r$ and $\theta$ parameters lead to a considerable increase in the total entropy generation number. Of course, it is worth noting that for high values of duct inclination angle, the effect of Grashof number on the $N s_{t}$ is much higher. Such that, the highest value of total entropy generation number occurs in the vertical ducts and at highest value of $G r$. 


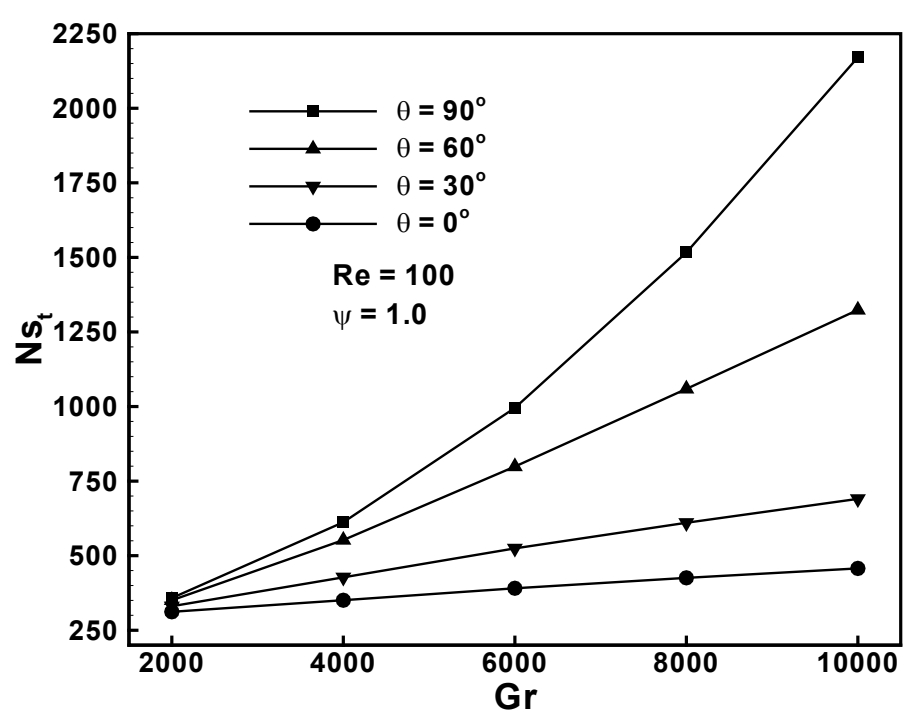

Fig. 8. Effect of Grashof number on the amount of total entropy generation number for different values of the duct inclination angle

But as it is seen from Figure 9, there are different trends for the changes of average Bejan number with $G r$ and $\theta$ parameters. According to this figure, the amount of $B e_{\text {ave }}$ decreases by increasing both $G r$ and $\theta$ parameters. However, it should be noted that similar to the results shown in Figure 8, the effect of Grashof number on the $B e_{\text {ave }}$ is increased by enhancement of the duct inclination angle. In fact, the lowest value of average Bejan number occurs at highest values of Gr and $\theta$ parameters.

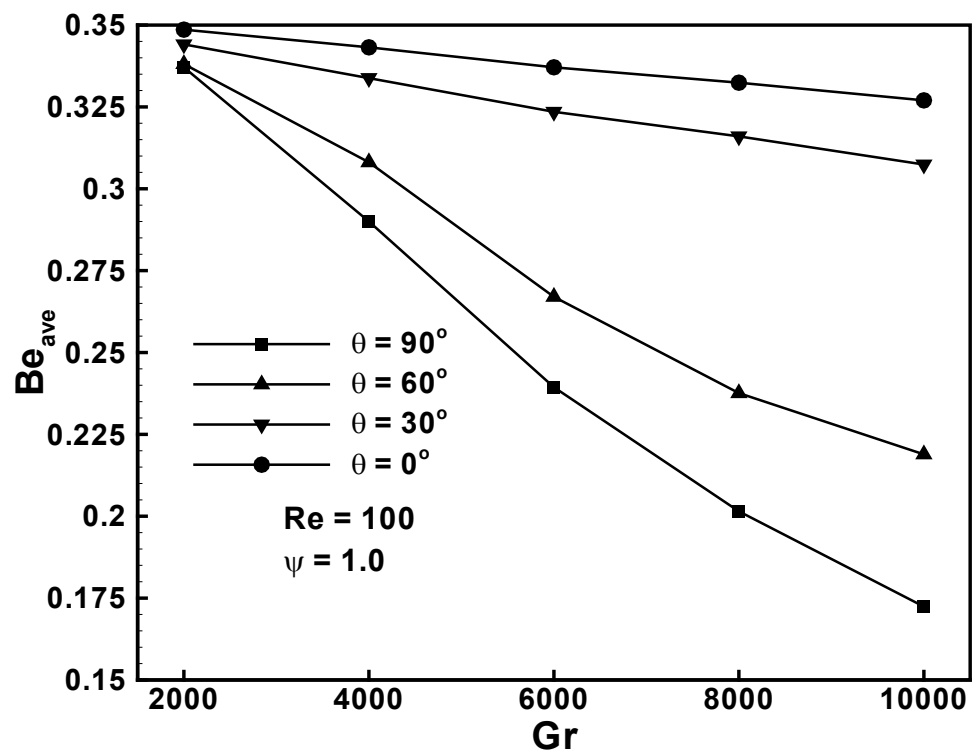

Fig. 9. Effect of Grashof number on the amount of average Bejan number for different values of the duct inclination angle 


\section{Conclusions}

In this paper, the effects of buoyancy force on the irreversibility of three-dimensional step flow in an inclined duct are analyzed. This analysis is done by calculating the entropy generation number based on the second law of thermodynamics. The following results can be drawn from this study:

- The values of entropy generation number increase significantly by increasing the Grashof numbers. This enhancement is more due to the considerable increase of viscous shear stresses against the value of $G r$.

- Any increase in the value of $G r$ causes a decrease in the maximum value of $B e$. Because the enhancement rate of $N s_{H}$ with increasing Grashof number is smaller than the increase rate of $N s_{V}$ against the value of $G r$.

- An enhancement in the values of total entropy generation number (flow irreversibility) is registered by increasing both the Grashof number and duct inclination angle. While any enhancement in these parameters leads to a significant decrease in the average Bejan number

- By increasing the duct inclination angle, the effect of Grashof number on the values of $N s_{t}$ and $B e_{a v e}$ is much higher.

\section{References}

Abu-Nada E (2006). Entropy generation due to heat and fluid flow in backward facing step flow with various expansion ratios. International Journal of Exergy. 3: 419-435.

Abu-Nada E (2008). Investigation of entropy generation over a backward facing step under bleeding conditions. Energy Conversion and Management. 49: 3237-3242.

Aghaei A, Khorasanizadeh H, Sheikhzadeh G, Abbaszadeh M (2016). Numerical study of magnetic field on mixed convection and entropy generation of nanofluid in a trapezoidal enclosure. Journal of Magnetism and Magnetic Materials. 403: 133-145.

Atashafrooz M, Gandjalikhan Nassab SA, Ansari AB (2011). Numerical study of entropy generation in laminar forced convection flow over inclined backward and forward facing steps in a duct. International Review of Mechanical Engineering. 5(5): 898-907.

Atashafrooz M, Gandjalikhan Nassab SA (2012). Simulation of three-dimensional laminar forced convection flow of a radiating gas over an inclined backward-facing step in a duct under bleeding condition. Institution of Mechanical Engineers, Part C, Journal of Mechanical Engineering Science. 227(2): 332-345.

Atashafrooz M, Gandjalikhan Nassab SA, Ansari AB (2014). Numerical investigation of entropy generation in laminar forced convection flow over inclined backward and forward facing steps in a duct under bleeding condition. Thermal Science. 18(2): 479-492.

Atashafrooz M, Gandjalikhan Nassab SA, Lari K (2015). Application of full-spectrum kdistribution method to combined non-gray radiation and forced convection flow in a duct with an expansion. Journal of Mechanical Science and Technology. 29(2): 845-859.

Bahaidarah HMS, Sahin AZ (2013). Thermodynamic analysis of fluid flow in channels with wavy sinusoidal walls. Thermal Science. 17(3): 813-822.

Bejan A (1994). Entropy generation through heat and fluid flow. John Wiley \& Sons Inc., Canada. Bejan A (1996). Entropy generation minimization. CRC Press, Boca Raton, New York, USA. 
Chen YT, Nie JH, Hsieh HT, Sun LJ (2006). Three-dimensional convection flow adjacent to inclined backward-facing step. International Journal of Heat and Mass Transfer. 49: 47954803.

Dagtekin I, Oztop HF, Bahloul A (2007). Entropy generation for natural convection in $\Gamma$-shaped enclosures. International Communications in Heat and Mass Transfer. 34 (4): 502-510.

Erbay LB, Altaç Z, Sülüş B (2004). Entropy generation in a square enclosure with partial heating from a vertical lateral wall. Heat and Mass Transfer. 40(12): 909-918.

Iwai H, Nakabe K, Suzuki K, Matsubara K (2000). The effects of duct inclination angle on laminar mixed convective flows over a backward-facing step. International Journal of Heat and Mass Transfer. 43: 473-485.

Kooshki, MS, Gandjalikhan Nassab SA, Ansari AB (2012). Investigation of entropy generation in 3-d laminar forced convection flow over a backward facing step with bleeding. International Journal of Engineering-Transactions A: Basics. 25(4): 379-388.

Mamourian M, Shirvan KM, Ellahi R, Rahimi AB (2016). Optimization of mixed convection heat transfer with entropy generation in a wavy surface square lid-driven cavity by means of Taguchi approach. International Journal of Heat and Mass Transfer. 102: 544-554.

Mohaghegh MR, Esfahani JA (2016). Entropy generation analysis of free convection from a constant temperature vertical plate using similarity solution. Thermal Science. 20(6): 18551866.

Mohammed HA, Alawi OA, Wahid MA (2015). Mixed convective nanofluid flow in a channel having backward-facing step with a baffle. Powder Technology. 275: 329-343.

Nassab SAG, Bahrami A, Keshtkar MM, Saffaripour MH (2014). Comparison between two methods for enhancing heat transfer in separated convection flows-second law analysis. Iran Journal of Science and Technology, Transactions of Mechanical Engineering. 38(M1): 923.

Nie JH, Chen YT, Hsieh HT (2009). Effects of a baffle on separated convection flow adjacent to backward-facing step. International Journal of Thermal Sciences. 48: 618-625.

Oztop HF, Kolsi L, Alghamdi A, Abu-Hamdeh N, Borjini MN, Aissia HB (2017). Numerical analysis of entropy generation due to natural convection in three-dimensional partially open enclosures. Journal of the Taiwan Institute of Chemical Engineers. 75: 131-140.

Patankar SV, Spalding DB (1972). A calculation procedure for heat, mass and momentum transfer in three-dimensional parabolic flows. International Journal of Heat and Mass Transfer. 15(10): 1787-1806.

Selimefendigil F, Oztop HF (2013). Numerical analysis of laminar pulsating flow at a backward facing step with an upper wall mounted adiabatic thin fin. Computers \& Fluids. 88: 93-107.

Selimefendigil F, Öztop HF (2015). Influence of inclination angle of magnetic field on mixed convection of nanofluid flow over a backward facing step and entropy generation. Advanced Powder Technology. 26(6): 1663-1675.

Selimefendigil F, Oztop HF (2016). Numerical study of forced convection of nanofluid flow over a backward facing step with a corrugated bottom wall in the presence of different shaped obstacles. Heat Transfer Engineering. 37(15): 1280-1292.

Uruba V, Jona's P, Mazur O (2007). Control of a channel-flow behind a backward-facing step by suction/blowing. International Journal of Heat and Fluid Flow. 28: 665-672.

\section{Nomenclature}

$\begin{array}{ll}A R & \text { Aspect ratio } \\ B e & \text { Bejan number } \\ D & \text { Width of the duct, }(\mathrm{m}) \\ E R & \text { Expansion ratio }\end{array}$


$h \quad$ Duct height upstream of the step, (m)

$H \quad$ Duct height downstream of the step, (m)

$k \quad$ Thermal conductivity, $\left(\mathrm{W} \cdot \mathrm{m}^{-1} \cdot \mathrm{K}^{-1}\right)$

$L_{1} \quad$ Duct length upstream of the step, (m)

$L_{2} \quad$ Duct length downstream of the step, (m)

Ns $\quad$ Entropy generation number

$p \quad$ Pressure, $\left(\right.$ N.m $\left.{ }^{-2}\right)$

$P \quad$ Dimensionless pressure

$P r \quad$ Prandtl number

Re Reynolds number

$S \quad$ Height of step, (m)

$S_{g} \quad$ Entropy generation rate

$T \quad$ Temperature, $(\mathrm{K})$

$U_{0} \bar{V} \quad$ Average velocity of the incoming flow at the inlet section $(\mathrm{m} / \mathrm{s})$

$u, v, w \quad \mathrm{x}-, \mathrm{y}$ - and z-components of velocity, $(\mathrm{m} / \mathrm{s})$

$U, V, W$ Dimensionless $\mathrm{x}-, \mathrm{y}-$ and z-component of velocity

\section{Greek Symbols}

$\begin{array}{ll}\alpha & \text { Thermal diffusivity, }\left(\mathrm{m}^{2} \cdot \mathrm{s}^{-1}\right) \\ \beta & \text { Step inclination angle } \\ \mu & \text { Dynamic viscosity, }\left(\mathrm{N} \cdot \mathrm{s} \cdot \mathrm{m}^{-2}\right) \\ \vartheta & \text { Kinematic viscosity, }\left(\mathrm{m}^{2} \cdot \mathrm{s}^{-1}\right) \\ \rho & \text { Density, }\left(\mathrm{kg} \cdot \mathrm{m}^{-3}\right) \\ \Theta & \text { Dimensionless temperature } \\ \gamma & \text { Constant volumetric expansion }\end{array}$

\section{Subscripts}

$\begin{array}{ll}c & \text { Cold wall } \\ \text { ave } & \text { Average } \\ h & \text { Hot wall } \\ H & \text { Heat transfer } \\ \text { in } & \text { Inlet section } \\ t & \text { Total } \\ V & \text { Viscous shear stresses }\end{array}$

